\title{
The biomimetic apatite-cefalotin coatings on modified titanium
}

\author{
Min-Kyung KANG ${ }^{1}$, Sang-Bae LEE ${ }^{1,2}$, Seung-Kyun MOON${ }^{1}$, Kwang-Mahn KIM¹ and Kyoung-Nam KIM ${ }^{1}$ \\ ${ }^{1} B K 21$, Department and Research Institute of Dental Biomaterials and Bioengineering, and Research Center for Orofacial Hard Tissue Regeneration, \\ College of Dentistry, Yonsei University, 50 Yonsei-ro, Seodaemun-gu, Seoul 120-752, Republic of Korea \\ 2Institute for Clinical Dental Research, Graduate School of Clinical Dentistry, Korea University, Seoul 120-752, Republic of Korea \\ Corresponding author, Kyoung-Nam KIM; E-mail: kimkn@yuhs.ac
}

\begin{abstract}
Dental implant failure often occurs due to oral bacterial infection. The aim of this study was to demonstrate that antibiotic efficacy could be enhanced with modified titanium. First, the titanium was modified by anodization and heat-treatment. Then, a biomimetic coating process was completed in two steps. Surface characterization was performed with scanning electron microscopy, energy dispersive spectroscopy, and X-ray diffraction. Release of antibiotic was evaluated by UV/VIS spectrometry, and the antibacterial effect was evaluated on Streptococcus mutans. After the second coating step, we observed a thick homogeneous apatite layer that contained the antibiotic, cefalotin. The titanium formed a rutile phase after the heat treatment, and a carbonated apatite phase appeared after biomimetic coating. We found that the modified titanium increased the loading of cefalotin onto the hydroxyapatite coated surface. The results suggested that modified titanium coated with a cefalotin using biomimetic coating method might be useful for preventing local post-surgical implant infections.
\end{abstract}

Keywords: Anodization, Antibacterial effect, Biomimetic coating, Cefalotin, Heat-treatment

\section{INTRODUCTION}

Several attempts have been made to improve the bonding between bone and a dental implant by coating the titanium of the implant with bioactive materials, like hydroxyapatite, which can form a chemical bond with bone tissue ${ }^{1-4)}$. Despite the development of this coating method, implants have continued to fail. An exposed implant can interact with negative bacteria, which can lead to infection around the implant. In addition, some patients that receive implants have had periodontitis in the past. A history of periodontitis and the presence of bacteria are risk factors for peri-implant infections ${ }^{5,6)}$. And this may ultimately result in implant failure. Therefore, many studies have addressed this problem with limited success ${ }^{7-12}$. Therefore, to solve this problem, local drug delivery system through antibiotic coatings was developed ${ }^{13-17)}$. Recently, precipitation coating method was introduced. In this biomimetic precipitation method, the titanium implant is immersed into saturated solutions of calcium and phosphate that also contain antibiotics. When the calcium-phosphate crystals were precipitated, the antibiotics were coprecipitated ${ }^{13-16)}$. Antibiotics that contain a carboxylic group, like cefalotin, have strong binding interactions with calcium. In vitro tests have shown that biomimetic coatings have high antibiotic incorporation efficiency and a slow release rate from the coated surface ${ }^{14}$. The cefalotin antibiotic is a first generation cephalosporin antibiotic. It is used to prevent infection during surgery and to treat many kinds of infections of the blood, bone or joints, respiratory tract, skin, and urinary tract. The bactericidal activity of cefalotin results from the inhibition of cell wall synthesis via affinity for penicillin-binding proteins (PBPs). The

Color figures can be viewed in the online issue, which is available at J-STAGE.

Received Jun 1, 2011: Accepted Sep 27, 2011

doi:10.4012/dmj.2011-131 JOI JST.JSTAGE/dmj/2011-131
PBPs are transpeptidases which are vital in peptidoglycan biosynthesis. Therefore, their inhibition prevents this vital cell wall compenent from being properly synthesized ${ }^{18)}$.

In this study, the titanium surface was modified by anodizing and heat-treatment before applying a biomimetic coating. We hypothesized that modifying the titanium surface could increase the quantities of antibiotic loaded into the coating. We reasoned that anodization would increase the porosity and the surface area compared to polished titanium ${ }^{19-21)}$. In addition, the heat-treatment could increase the crystallinity of the titania layer ${ }^{22}$. Thus, these morphological and phase modification could enhance the precipitation of calciumphosphate.

The aim of this study was to demonstrate that modifying the titanium surface would result in an increased loading of the antibiotic cefalotin onto a biomimetic hydroxyapatite coating. In addition, antibiotic efficacy was evaluated to determine whether this method would improve antibacterial effect.

\section{MATERIALS AND METHODS}

\section{Preparation of specimen}

The present study was performed with commercially pure titanium (cp-Ti; $10 \times 10 \times 0.25 \mathrm{~mm}$ ). The titanium surfaces were polished mechanically with SiC paper with grits of 100,600, and 1,200 and cleaned ultrasonically in acetone, ethanol, and distilled water for $15 \mathrm{~min}$. Then, the titanium was anodized at $300 \mathrm{~V}$ for $2 \mathrm{~min}$ with a DC power supply (Genesys 600-2.6, Densi-Lambda, TDK, Tokyo, Japan). As the electrolyte, $0.4 \mathrm{M}$ calcium acetate (CA) and 0.04 M beta-glycerol phosphate disodium salt $n$-hydrate $(\beta$-GP) mixed solution was used. The anodizing apparatus is shown schematically in Fig. 1. After 


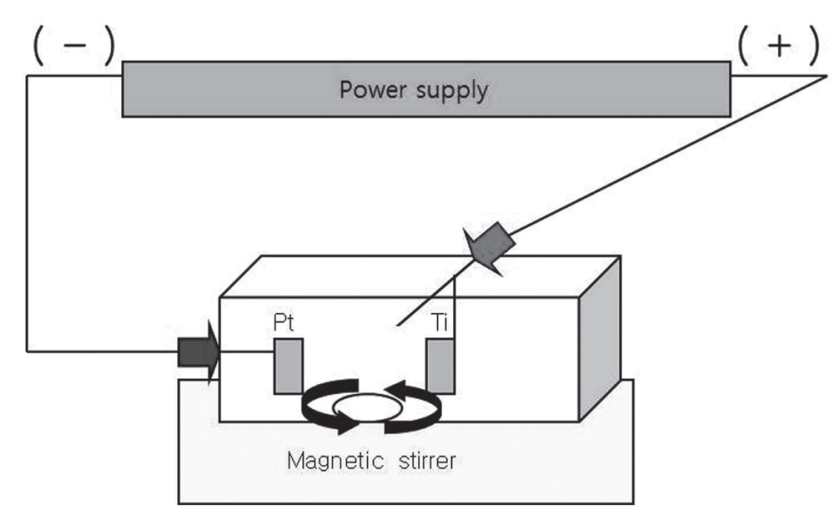

Fig. 1 Schematic diagram of the apparatus for anodization.

Table 1 Experimental groups used in this study

\begin{tabular}{ll}
\hline Group & \multicolumn{1}{c}{ Description } \\
\hline 1 & Polishing \\
2 & polishing+Anodizing \\
3 & polishing+Anodizing+Heat treatment \\
\hline
\end{tabular}

anodization, the titanium was heated to $800^{\circ} \mathrm{C}$ for $4 \mathrm{~h}$ in the air atmosphere (BF51800 sreies, Lindberg/Blue M, TPS, White Deer, PA, U.S.A) to change the crystalline phase. Therefore, three experimental groups were divided according to the different procedures, as shown in Table 1.

\section{Biomimetic coating process}

The coating process was performed in two steps. In the first step, the titanium was coated with a layer of calcium phosphate by immersing five times in concentrated simulated body fluid (SBF A; $733 \mathrm{mM} \mathrm{NaCl}, 21 \mathrm{mM}$ $\mathrm{NaHCO}_{3}, 5 \mathrm{mM} \mathrm{NaH} \mathrm{PO}_{4} \cdot 2 \mathrm{H}_{2} \mathrm{O}, 7.5 \mathrm{mM} \mathrm{MgCl}{ }_{2} \cdot 6 \mathrm{H}_{2} \mathrm{O}$, $12.5 \mathrm{mM} \mathrm{CaCl}_{2} \cdot 2 \mathrm{H}_{2} \mathrm{O}$ ) at $37^{\circ} \mathrm{C}$ for $24 \mathrm{~h}^{14)}$. The SBF A was adjusted to a $\mathrm{pH}$ of 7.4 with $1 \mathrm{M} \mathrm{NaOH}$ and $1 \mathrm{M}$ HEPES (4-(2-hydroxyethyl)-1-piperazineethanesulfonic acid) buffer. The salts were dissolved by bubbling gas $\mathrm{CO}_{2}$ in the solution. When the $\mathrm{pH}$ dropped to 6.0, the $\mathrm{CO}_{2}$ bubbling was terminated. After $24 \mathrm{~h}$, the $\mathrm{pH}$ had reached approximately 8.0; then, the titanium was rinsed in distilled water and dried overnight at room temperature. In the second step, the titanium was coated with a layer of calcium phosphate that contained an antibiotic. Titanium from the first step was immersed in another calcium phosphate supersaturated solution (SBF B; 146 $\mathrm{mM} \mathrm{NaCl}, 1 \mathrm{mM} \mathrm{NaHCO}, 2 \mathrm{mM} \mathrm{NaH}_{2} \mathrm{PO}_{4} \cdot 2 \mathrm{H}_{2} \mathrm{O}, 0.05$ $\left.\mathrm{mM} \mathrm{MgCl}_{2} \cdot 6 \mathrm{H}_{2} \mathrm{O}, 4 \mathrm{mM} \mathrm{CaCl} \cdot 2 \mathrm{H}_{2} \mathrm{O}\right)$ containing 800 $\mathrm{mg} / \mathrm{L}$ of cefalotin ${ }^{14)}$. After $48 \mathrm{~h}$ at $37^{\circ} \mathrm{C}$, the titanium was removed from the solution, and then dried at $50^{\circ} \mathrm{C}$ for 30 $\min$.

\section{Surface characterization}

The surface morphology and elements were examined by field-emission scanning electron microscopy (FE-SEM, JSM-6700F, Jeol, Tokyo, Japan) and electron dispersive spectroscopy (EDS), respectively. The surface layer phases were analyzed with a High Resolution X-ray Diffractomer (HRXRD, Bruker D8 DISCOVER, Karlsruhe, Germany).

\section{In vitro release of antibiotic}

Each specimen was immersed in $5 \mathrm{~mL}$ distilled water in a glass vial. The vials were stored at $37^{\circ} \mathrm{C}$ for $1,2,4,7$, 14, 30 and 60 days. At the indicated time intervals, the distilled water was collected to measure antibiotic concentration, and then refreshed. The antibiotic concentration was measured with an UV/VIS spectrometer (Spectro UV-VIS double beam PC, USD-3200, Labomed Inc, Culver city, CA, U.S.A.) at 236 $\mathrm{nm}(n=10)$.

\section{Evaluation of antibacterial activity}

Antibacterial activity was evaluated with a film adhesion method. This method modified ISO 22196: Plasticsmeasurement of antibacterial activity on plastic surfaces and JIS Z 2901; Antibcaterial products- Test for antibacterial activity and efficacy. Firstly, Streptococcus mutans (S. mutans; IFO 13955) which were abundant bacteria found almost universally in the mouths and the earliest colonizer were cultured aerobically in a conical tube that contained $100 \mathrm{~mL}$ Brain Heart Infusion (BHI) medium at $37^{\circ} \mathrm{C}$. The initial concentration of bacteria was adjusted to $10^{6}-10^{5}$ colony-forming units (CFU)/mL by dilution with phosphate-buffered saline (Invitrogen, GIBCO, gland Island, NY, U.S.A.) (PBS, pH 7.2). To test for antibiotic efficacy, $50 \mu \mathrm{L}$ of bacterial solution was pipetted onto each specimen. And specimen was covered with polyethylene film. This procedure was conducted under dark condition to avoid photocatalytic activity. After $4 \mathrm{~h}$, the specimen was rinsed with $1 \mathrm{~mL}$ PBS and bacterial cells were detached by sonication in PBS. And $100 \mu \mathrm{L}$ of harvested cells were plated onto Bacto-Agar plates. Plates were incubated for $48 \mathrm{~h}$ at $37^{\circ} \mathrm{C}$ to determine the number of viable $S$. mutans (expressed in CFUs). $(n=15)$. The uncoated titanium was used as a control.

\section{Statistical analysis}

Results of the antibacterial activity test were analyzed with the one-way ANOVA test to compare significant differences. The significance level was set at $95 \%$.

\section{RESULTS AND DISCUSSION}

\section{Surface characterization}

FE-SEM images showed the modified titanium specimens before the coating process (Fig. $2 \mathrm{a}-\mathrm{c}$ ). The treatment for groups 2 and 3 increased the surface area compared to group 1 (polished titanium). The mean surface roughness $\left(R_{\mathrm{a}}\right)$ of modified titanium was about $0.4 \mu \mathrm{m}$. In contrast, the $R_{\mathrm{a}}$ of polished titanium was $0.2 \mu \mathrm{m}$ (data not shown). 


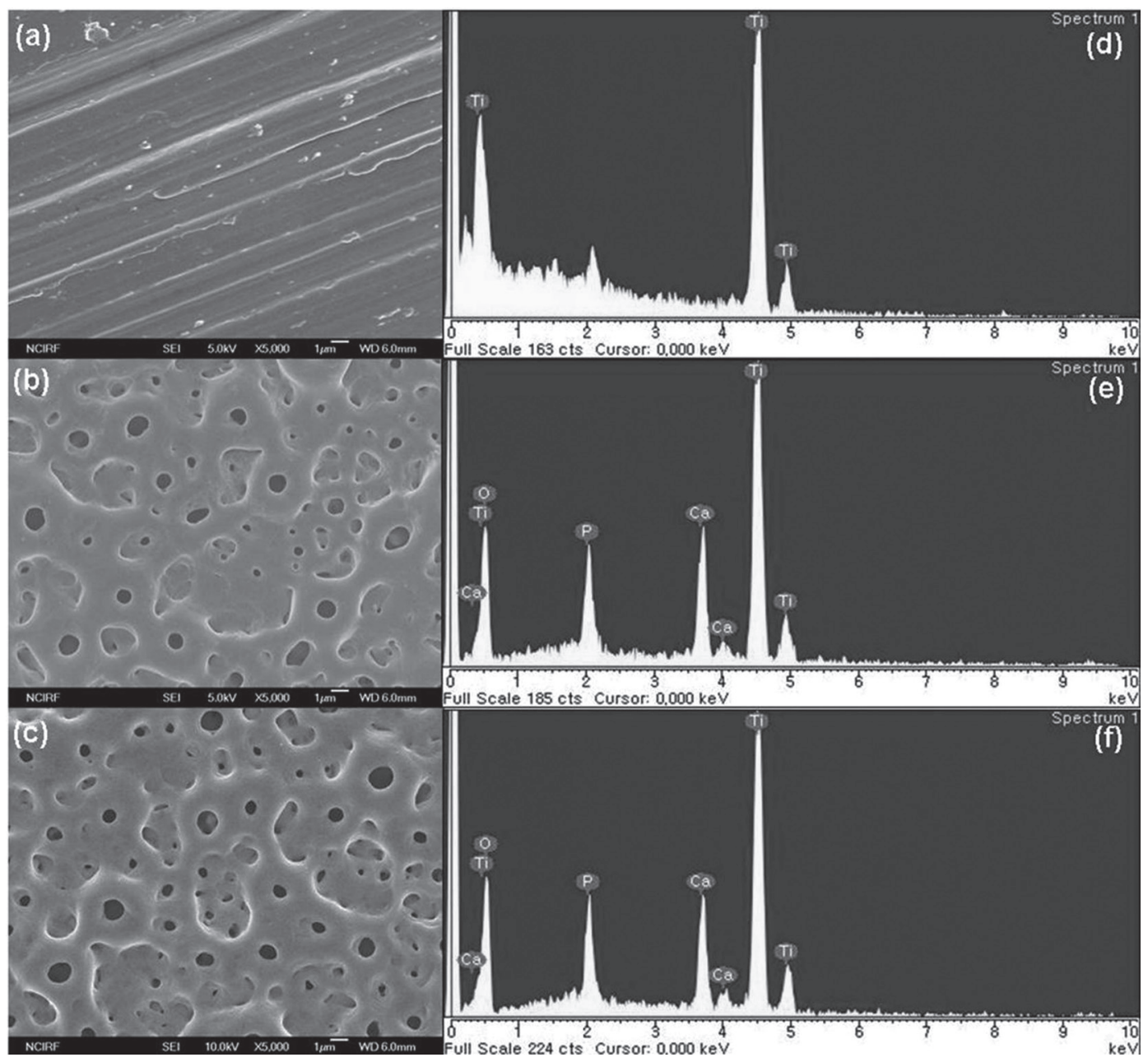

Fig. 2 Characteristics of modified titanium. (Left) Field-emission scanning electron microscopy images show the surface morphologies of modified titanium implant models $(\times 5,000)$ : (a) Group 1: polished, (b) Group 2: polished and anodized (c) Group 3: polished, anodized, and heat-treated. (Right) Electron dispersive spectroscopy analyses identified elements on the surfaces of modified titanium: (d) Group 1, (e) Group 2, (f) Group 3.

After anodization, micro-structures had formed on the surface. This did not change after heat-treatment. The pore sizes both before and after heat treatment were less than $2 \mu \mathrm{m}^{23)}$. In the elemental analysis by EDS (Fig. 2d-f), Ca and P were detected on anodized, heat-treated titanium, but not polished titanium. It could explain that $\mathrm{Ca}$ and $\mathrm{P}$ ions contained in the electrolyte solution would penetrate the inside of the oxide layer ${ }^{19)}$. After the biomimetic coating process, morphological and elemental analyses of the titanium were also performed (Fig. 3 and 4). After the first step (Fig. $3 \mathrm{a}-\mathrm{c}$ ), the titanium was covered with loose calcium phosphate particles. The coated surface appeared globular. These globules would be nucleation sites for the growing calcium phosphate crystals $^{24)}$. And more $\mathrm{Ca}$ and $\mathrm{P}$ could detect on the titanium surface (Fig. 3d-f) compared to titanium before the coating process (Fig. 2d-f). After the second step (Fig. 4), the modified titanium surface (Group 2 and 3) were homogeneously covered with well-formed calcium phosphate crystals; this contrasted with the polished titanium surface because modified titanium had higher number of nucleation sites due to larger surface area compared to polished titanium as shown Fig.3. In contrast, the coating on polished titanium formed a heterogeneous layer ${ }^{24}$. This biomimetic coating reaction could occur due to an increased solubility of calcium phosphate salts with the addition of the acidic gas, $\mathrm{CO}_{2}{ }^{25)}$. In addition, the $\mathrm{SBF} \mathrm{B}$ solution had lower $\mathrm{Mg}$ and $\mathrm{HCO}_{3}$ ion content than the SBF A solution. These ions can inhibit crystallization. Therefore, the second coating formed a thick, homogenous calcium phosphate layer compared to the first coating ${ }^{24-29)}$. As shown in the EDS results, Mg was not detected in the second coating, unlike the first coating. $\mathrm{Ca}$ and $\mathrm{P}$ were increased after second coating. And $\mathrm{C}$ peak was showed also. The Table 2 shows the composition of specimen from EDS.

Figure 5 shows the XRD results of modified titanium prior to the biomimetic coating. The anodization process 

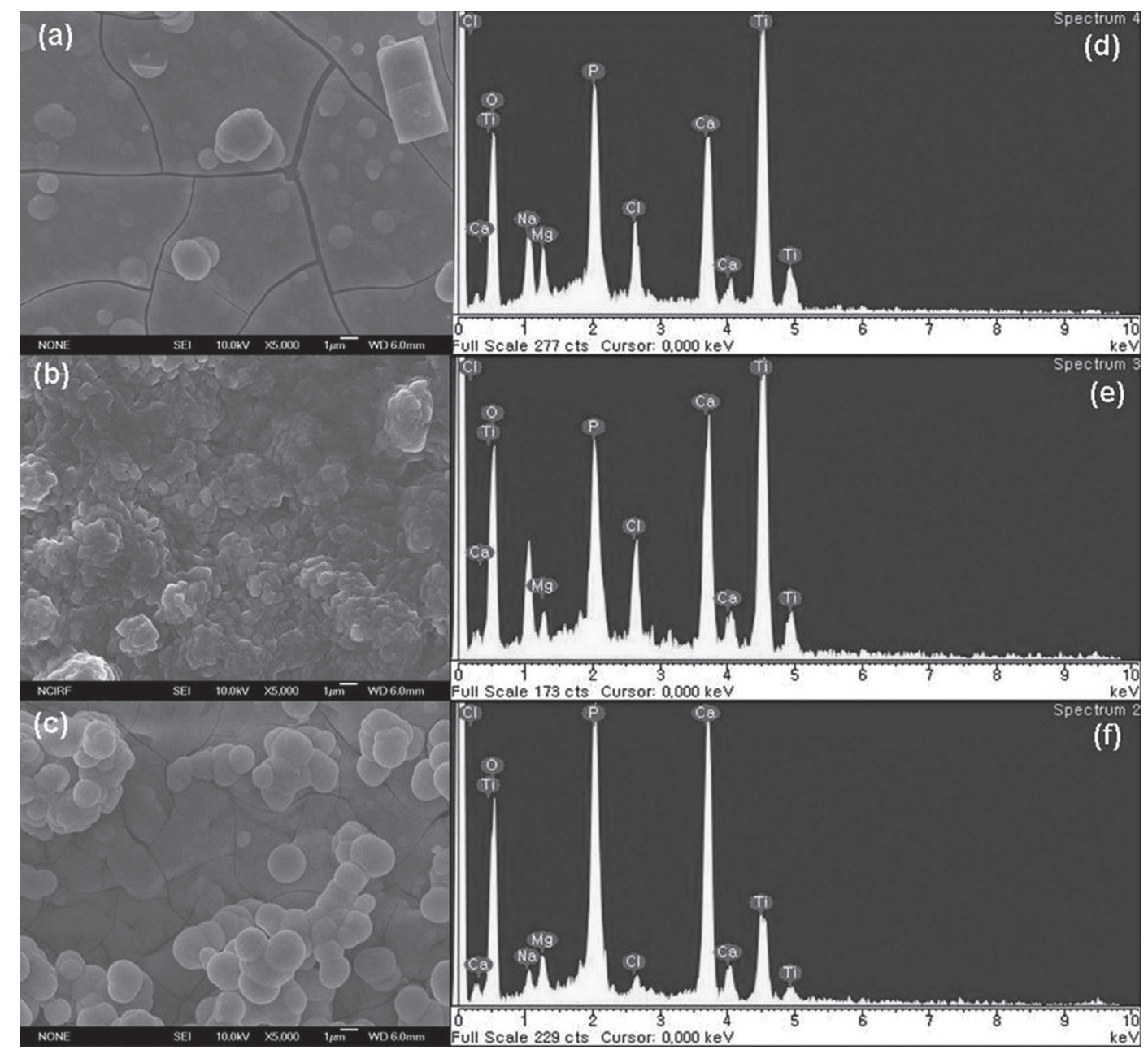

Fig. 3 Characteristics of modified titanium after first biomimetic coating. (Left) Field-emission scanning electron microscopy images show the surface morphologies of the titanium after the first biomimetic coating $(\times 5,000)$ : (a) Group 1: polished, (b) Group 2: polished and anodized, (c) Group 3: polished, anodized, and heat-treated. Electron dispersive spectroscopy analyses identified elements on the surfaces of modified titanium after the first biomimetic coating: (d) Group 1, (e) Group 2, (f) Group 3.

induced the titanium to form an anatase phase. Titanium and oxygen ion underwent a redox reaction that resulted in the formation of a titanium oxide film. The heat-treated titanium exhibited both anatase and rutile phases together. In addition, $\mathrm{Ca}_{3}\left(\mathrm{PO}_{4}\right)_{2}$ was also observed. These results indicated that heat treatment improved the crystallinity of titanium oxide and calcium phosphate (Fig. 5) ${ }^{30)}$. In contrast, polished titanium showed only an alpha titanium phase (Fig. 5). The phase of surface could have influence on accumulation of calcium phosphate. As shown Fig. 6, after the biomimetic coating process, negatively charged $\mathrm{HPO}_{4}{ }^{2-}$ ions in the solution were chemically absorbed into the $\mathrm{CaTiO}_{3}$ surface (Fig. 6). $\mathrm{TiO}_{2}$ on Ti surface can be transformed in to $\mathrm{CaTiO}_{3}$ which is in contact aqueous solution containing sufficient $\mathrm{Ca}$, at a suitable $\mathrm{pH}$ and temperature. This chemical bond is capable of strengthening the adhesion between the apatite and $\mathrm{CaTiO}_{3}$ surfaces ${ }^{31)}$. In addition, titanium with an anatase and/or rutile crystal structure also showed excellent apatite-forming ability ${ }^{22,25,32)}$. In other words, the apatite-forming ability was related to the crystallinity of the titanium surface. The anodized titanium surface had a lower crystal order compared to heat-treated titanium ${ }^{33)}$. Therefore, Fig. 4 showed that carbonated apatite formed more readily on the heat-treated titanium surface than on the polished surfaces. The carbonate was able to substitute for phosphate, which results in the transformation of HA in to carbonated apatite. This carbonated apatite is similar to bone ${ }^{24)}$.

\section{Release of antibiotic}

Figure 7 shows the release of antibiotic from the coated titanium surface as a function of time. Most of the loaded cefalotin was released during the first day. A burst release of antibiotic will influence initial bacterial 


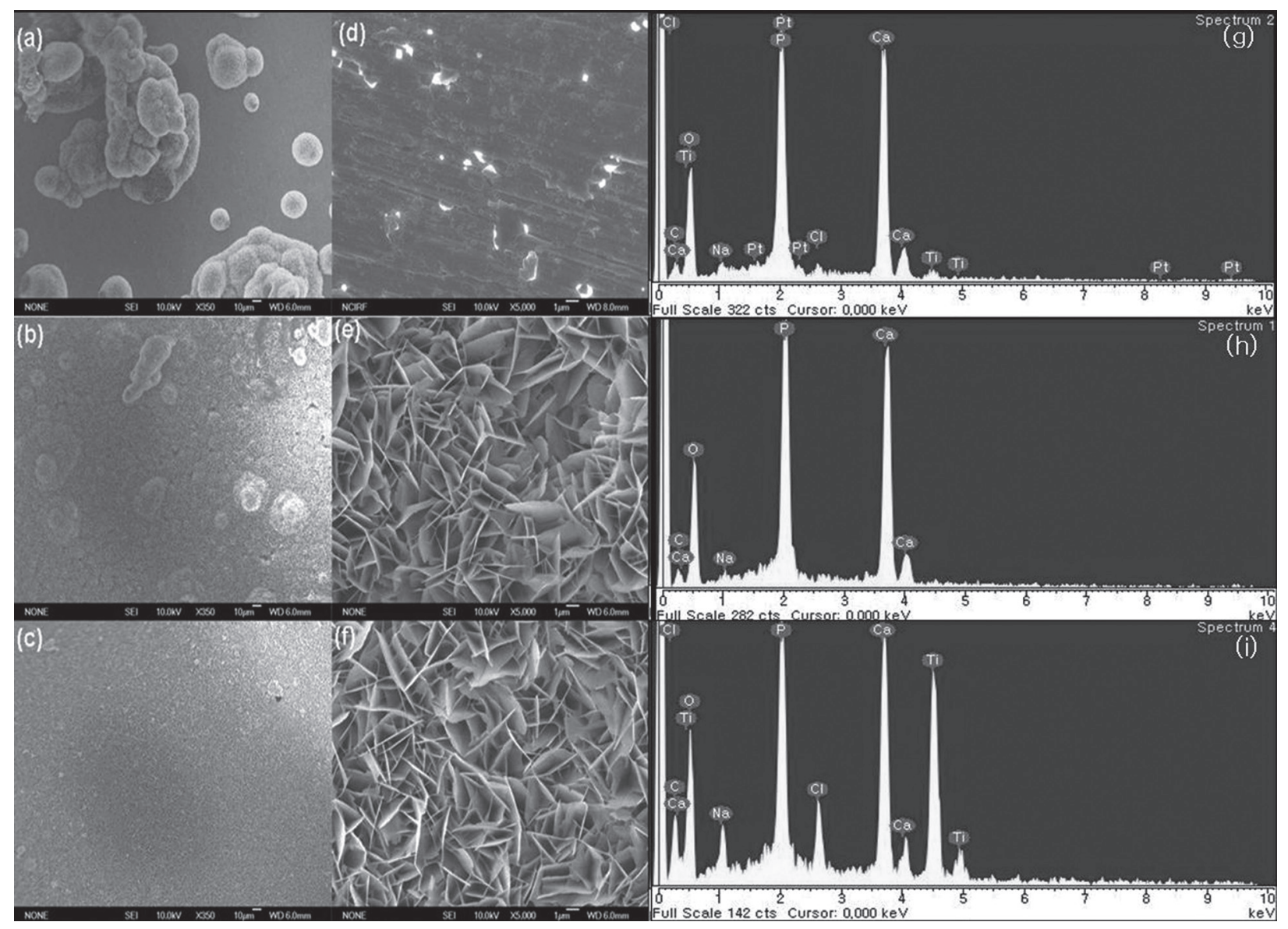

Fig. 4 Characteristics of modified titanium after second biomimetic coatings. (Left) Field-emission scanning electron microscopy images show the surface morphologies of the titanium after the second biomimetic coating $(\times 350, \times 5,000)$ : (a, d) Group 1: polished, (b, e) Group 2: polished and anodized, (c, f) Group 3: polished, anodized, and heat-treated. Electron dispersive spectroscopy analyses identified elements on the surfaces of titanium after the second biomimetic coating: (g) Group 1, (h) Group 2, (i) Group 3.

Table 2 Chemical composition of biomimetic coated titanium

\begin{tabular}{lccc}
\hline Group & 1 & 2 & 3 \\
Element composition & First biomimetic coating & First biomimetic coating & First biomimetic coating \\
\cline { 2 - 4 } (atm. \%) & Second biomimetic coating & Second biomimetic coating & Second biomimetic coating \\
\hline \multirow{2}{*}{$\mathrm{Ti}$} & 16.83 & 16.22 & 10.92 \\
& 11.66 & 5.7 & 4.62 \\
$\mathrm{Ca}$ & 4.64 & 7.2 & 9.03 \\
& 12.94 & 20.01 & 23.45 \\
$\mathrm{P}$ & 5.64 & 5.92 & 8.08 \\
& 12.31 & 21.99 & 23.98 \\
$\mathrm{O}$ & 61.00 & 63.05 & 68.47 \\
& 30.29 & 37.99 & 16.74 \\
$\mathrm{Mg}$ & 1.94 & 1.52 & 1.58 \\
& - & - & - \\
$\mathrm{Cl}$ & 2.51 & 3.09 & 0.57 \\
& 2.31 & 2.21 & 2.83 \\
$\mathrm{Na}$ & 3.95 & 3.0 & 1.35 \\
$\mathrm{C}$ & 2.94 & 2.41 & 3.19 \\
& - & - & - \\
\end{tabular}




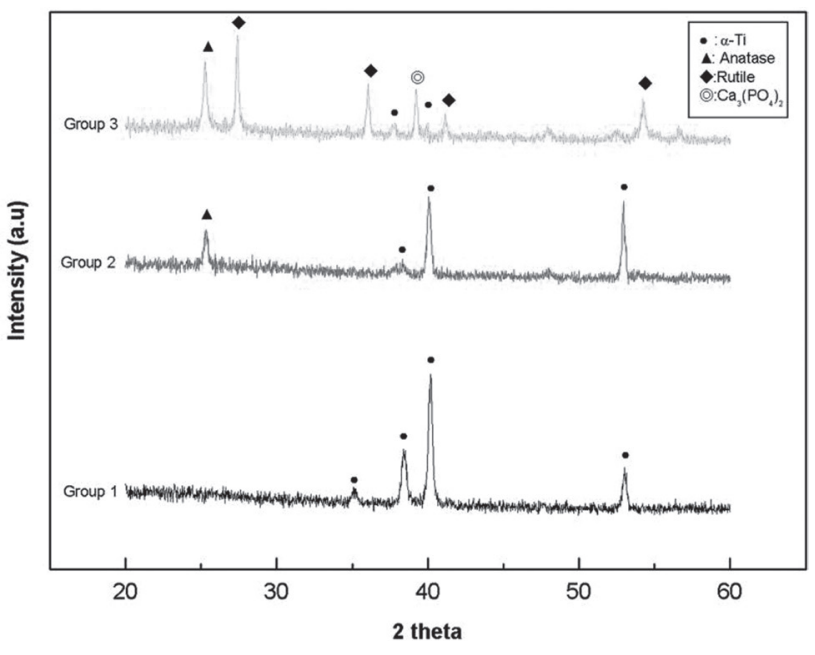

Fig. 5 High resolution X-ray diffraction patterns of modified titanium before the biomimetic coating. Group 1: polished, Group 2: polished and anodized, Group 3: polished, anodized, and heattreated.

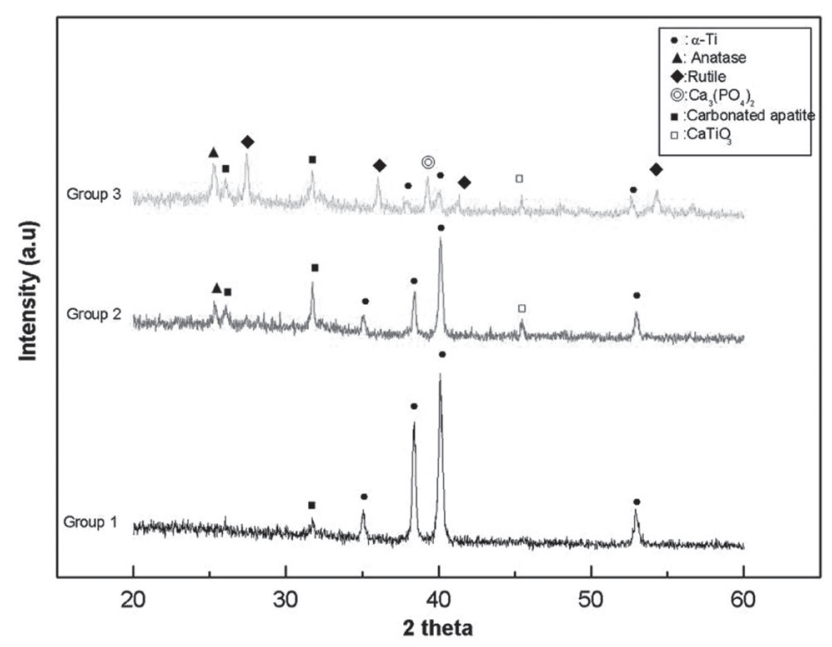

Fig. 6 High resolution X-ray diffraction patterns of modified titanium after the second biomimetic coating. Group 1: polished, Group 2: polished and anodized, Group 3: polished, anodized, and heattreated.

colonization. The heat treated titanium (Group 3) enhanced the ability of antibiotic to incorporate onto the surface, which increased the loading of cefalotin. Because the rutile structure of heat-treated titanium played an important role in inducing calcium phosphate deposition. In addition, the rutile structure allowed lattice matching between the titanium and apatite ${ }^{22,25,32)}$. Therefore, as the coated layer grew, the deposition of antibiotic on the heat-treated titanium might have been accelerated. This co-precipitation mechanism was also corroborated by Stigter and coworkers. They demonstrated that

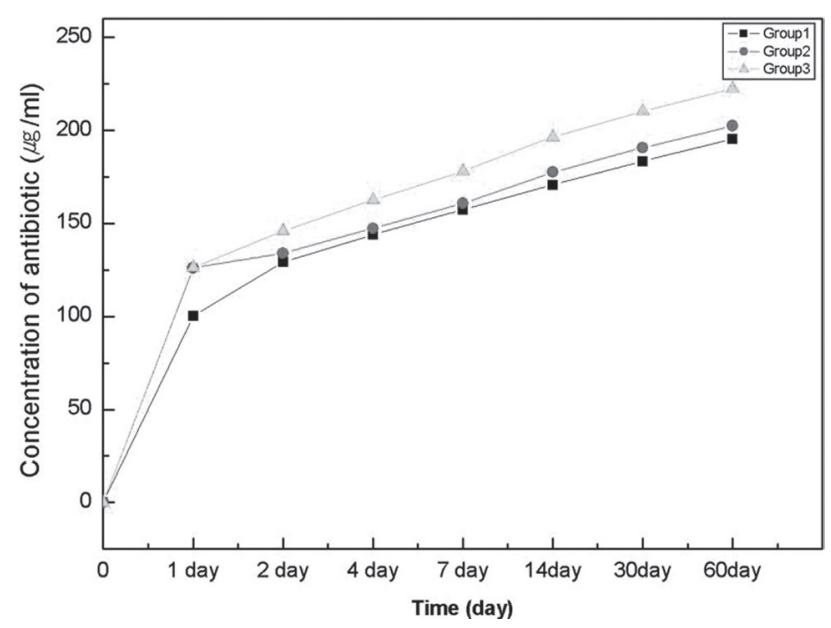

Fig. 7 Cumulative release of antibiotic from coated titanium over time. Group 1: polished; Group 2: polished and anodized; Group 3: polished, anodized, and heat-treated.

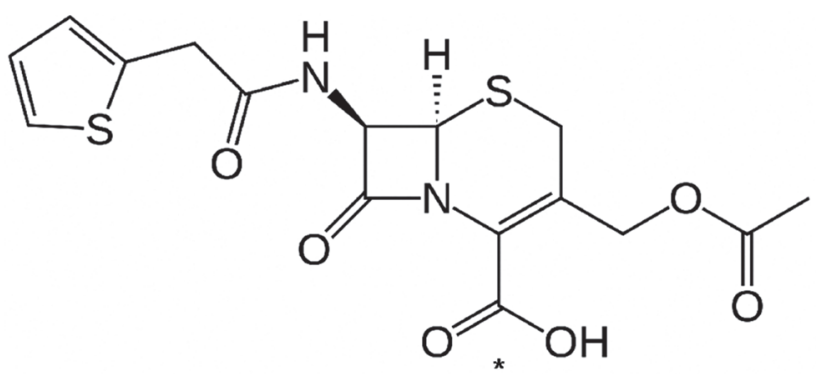

Fig. 8 Structure of the antibiotic, cefalotin. *Indicates the carboxyl group that binds to calcium.

tobramycin had an affinity for calcium phosphate surfaces and showed a correlation between the concentration of antibiotic in solution and the loading of tobramycin onto a calcium phosphate coated surface ${ }^{13)}$. In this study, carboxyl group in the chemical structure of cefalotin (Fig. 8) would confer strong binding to calcium ions; this facilitated the coprecipitation with apatite. In addition, the modified titanium (Group 2 and 3) had calcium ions on the surface (Fig. 2). Therefore, modified titanium could have enhanced the incorporation efficiency of cefalotin compared to polished titanium. The release mechanism of cefalotin is related to apatite dissolution though we didn't evaluate it yet. So, to observe the release rate, weight loss should be measured in the future.

\section{Evaluation of antibacterial activity}

Next, antibacterial activity test of coated titanium was performed (Fig. 9). The viability of S. mutans was tested after a 4 -h exposure to each specimen. The CFUs of $S$. mutans decreased after exposure to titanium specimens, 


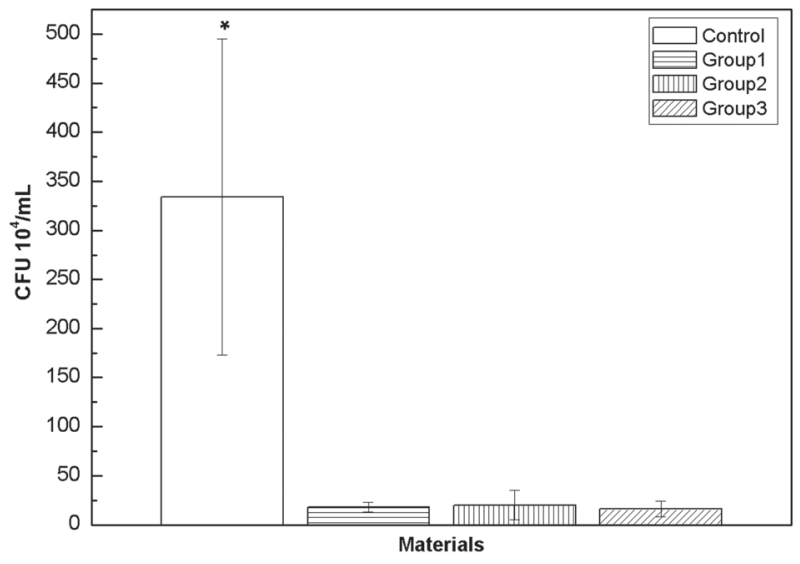

Fig. 9 Comparison of the number of $S$. mutans CFUs in the antibacterial activity test after exposure to coated titanium. Group 1: polished; Group 2: polished and anodized; Group 3: polished, anodized, and heat-treated.

* : Statically significant difference to experimental group $(p<0.05)$.

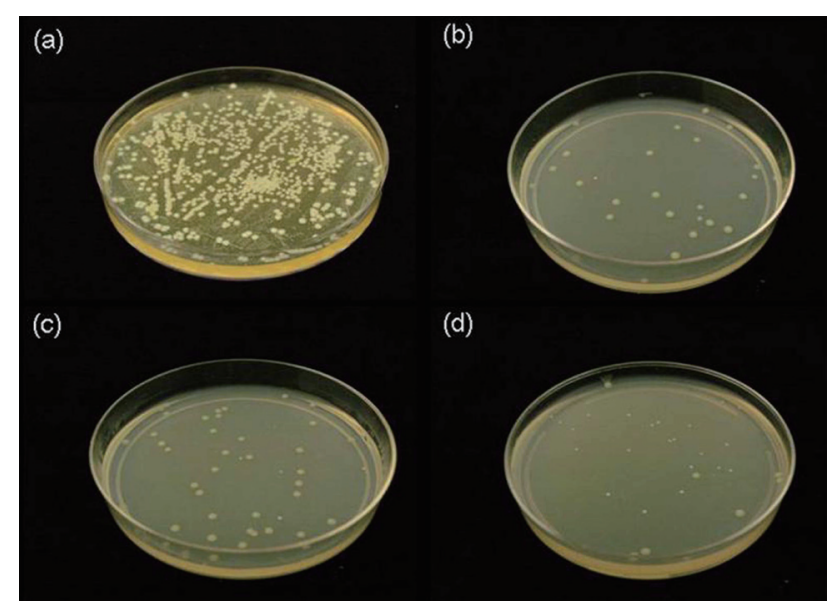

Fig. 10 Representative agar plates with $S$. mutans colonies displays the antibacterial effects of the coated titanium. (a) control (untreated) (b) Group 1: polished, (c) Group 2: polished and anodized, (d) Group 3: polished, anodized, and heat-treated.

in the following order: uncoated titanium (control) > polished, anodized titanium (group 2) > polished titanium (group 1) > polished, anodized, and heat-treated titanium (group 3). All the experimental groups showed reduced CFUs compared to the control group $(p<0.05)$ (Fig. 9). However, agar plates for the experimental group 1, 2 and 3 showed a similar number of $S$. mutans CFUs $(p>0.05)$ (Fig. 10); this might be related to the burst release of antibiotic. Thus, all experimental groups had a sufficient antibacterial effect against $S$. mutans in that time that corresponded to immediately after surgery. However, it is necessary to ensure a sustained antibiotic release from the coated surface, because peri-implantitis is slow developing ${ }^{5)}$. Also, a sustained antibiotic release may improve the safety of the dose and avoid side effects that can cause problems ${ }^{16)}$.

\section{CONCLUSIONS}

In this study, cefalotin was co-precipitated with carbonated apatite applied with a biomimetic coating method. A modified titanium surface increased the quantity of antibiotic that could be loaded onto the coated surface. Therefore, these results suggested that a cefalotin coating applied with a biomimetic coating method on modified titanium might be a promising material for preventing local post-surgical implant infections. However, further study is necessary to ensure the cytocompatibility and safety of this material.

\section{ACKNOWLEDGMENT}

This research was supported by the Basic Science Research Program through the National Research Foundation of Korea (NRF), funded by the Ministry of Education, Science and Technology (R13-2003-01303001-0).

\section{REFERENCES}

1) Song W-H, Jun Y-K, Han Y, Hong S-H. Biomimetic apatite coatings on micro-arc oxidized titania. Biomaterials 2004; 25: 3341-3349.

2) Manara S, Paolucci F, Palazzo B, Marcaccio M, Foresti E, Tosi G, Sabbatini S, Sabatino P, Altankov G, Roveri N. Electrochemically-assisted deposition of biomimetic hydroxyapatite-collagen coatings on titanium plate. Inorganica Chimica Acta 2008; 361: 1634-1645.

3) Avs EP, Estvez GF, Sader MS, Sierra JC, Yurell JC, Bastos IN, Soares GD. Hydroxyapatite coating by sol-gel on Ti-6Al-4V alloy as drug carrier. J Mater Sci Mater Med 2009; 20: 543-547.

4) Wang J, Chao Y, Wan Q, Yan K, Meng Y. Fluoridated hydroxyapatite/titanium dioxide nanocomposite coating fabricated by a modified electrochemical deposition. J Mater Sci Mater Med 2009; 20: 1047-1055.

5) Klinge Bn, Hultin M, Berglundh T. Peri-implantitis. Dent Clin North Am 2005; 49: 661-676.

6) Heitz-Mayfield LJA. Peri-implant diseases: diagnosis and risk indicators. J Clin Periodontol 2008; 35: 292-304.

7) Quirynen M, Soete MD, Steenberghe Dv. Infectious risks for oral implants: a review of the literature. Clin Oral Implants Res 2002; 13: 1-19.

8) Yoshinari M. Influence of surface modifications to titanium on antibacterial activity in vitro. Biomaterials 2001; 22: 2043-2048.

9) Läge K, Herold M, Scheideler L, Geis-Gerstorfer Jg, Wendel H-P, Gauglitz Gt. Investigation of initial pellicle formation on modified titanium dioxide $\left(\mathrm{TiO}_{2}\right)$ surfaces by reflectometric interference spectroscopy (RIfS) in a model system. Dent Mater 2004; 20: 814-822.

10) Yoshinari M, Oda Y, Kato T, Okuda K, Hirayama A. Influence of surface modifications to titanium on oral bacterial adhesion in vitro. J Biomed Mater Res 2000; 52: 388-394.

11) Pier-Francesco A, Adams RJ, Waters MGJ, Williams DW. Titanium surface modification and its effect on the adherence of Porphyromonas gingivalis: an in vitro study. Clin Oral 
Implants Res 2006; 17: 633-637.

12) Bügers R, Gerlach T, Hahnel S, Schwarz F, Handel G, Gosau M. In vivo and in vitro biofilm formation on two different titanium implant surfaces. Clin Oral Implants Res 2010; 21: 156-164.

13) Stigter M, de Groot K, Layrolle P. Incorporation of tobramycin into biomimetic hydroxyapatite coating on titanium. Biomaterials 2002; 23: 4143-4153.

14) Stigter M, Bezemer J, de Groot K, Layrolle P. Incorporation of different antibiotics into carbonated hydroxyapatite coatings on titanium implants, release and antibiotic efficacy. $J$ Control Release 2004; 99: 127-137.

15) Moojen DJF, Vogely HC, Fleer A, Nikkels PGJ, Higham PA, Verbout AJ, Castelein RM, Dhert WJA. Prophylaxis of infection and effects on osseointegration using a tobramycinperiapatite coating on titanium implants - An experimental study in the rabbit. J Orthop Res 2009; 27: 710-716.

16) Brohede U, Forsgren J, Roos S, Mihranyan A, Engqvist H, Strømme M. Multifunctional implant coatings providing possibilities for fast antibiotics loading with subsequent slow release. J Mater Sci Mater Med 2009; 20: 1859-1867.

17) Adams CS, Jr. VA, Harrison G, Patal P, Freeman TA, Shapiro IM, Parvizi J, Hickok NJ, Radin S, Ducheyne P. Controlled release of vancomycin from thin sol-gel films on implant surfaces successfully controls osteomyelitis. J Orthop Res 2009; 27: 701-709.

18) Shigi Y, Matsumoto Y, Kaizu M, Fujishta Y, Kojo H. Mechanism of action of new orally active cephalosporin FK027. J Antibiot 1984; 37: 790-296.

19) Zhu X, Kim K-H, Jeong Y. Anodic oxide films containing Ca and $\mathrm{P}$ of titanium biomaterial. Biomaterials 2001; 22: 2199-2206.

20) Zhu X, Ong JL, Kim S, Kim K. Surface characteristics and structure of anodic oxide films containing $\mathrm{Ca}$ and $\mathrm{P}$ on a titanium implant material. J Biomed Mater Res 2002; 60: 333-338.

21) Park IS, Woo TG, Jeon WY, Park HH, Lee MH, Bae TS, Seol KW. Surface characteristics of titanium anodized in the four different types of electrolyte. Electrochimica Acta 2007; 53: 863-870.
22) Yang B, Uchida M, Kim H-M, Zhang X, Kokubo T. Preparation of bioactive titanium metal via anodic oxidation treatment. Biomaterials 2004; 25: 1003-1010.

23) Ishizawa H, Ogino M. Formation and characterization of anodic titanium oxide films containing $\mathrm{Ca}$ and P. J Biomed Mater Res 1995; 29: 65-72.

24) Kunze J, Müler L, Macak JM, Greil P, Schmuki P, Müler FA. Time-dependent growth of biomimetic apatite on anodic $\mathrm{TiO}_{2}$ nanotubes. Electrochimica Acta 2008; 53: 6995-7003.

25) Habibovic P, Barrere F, van Blitterswijk CA, Groot Kd, layrolle P. Biomimetic hydroxyapatite coating on metal implants. J Am Ceram Soc 2002; 85: 517-522.

26) Barère F, Layrolle $P$, van Blitterswijk CA, de Groot K. Fast formation of biomimetic Ca-P coatings on Ti6Al4V. Mater Res Symp Proc 2000; 599: 135-140.

27) Füredi-Milhofer H, Brecevic L, Purgaric B. Crystal growth and phase transformation in the precipitation of calcium phosphates. Faraday Discuss Chem Soc 1976; 61: 184-190.

28) Koutsoukos P, Amjad Z, Tomson MB, Nancollas GH. Crystallization of calcium phosphate: a constant composition study. J Am Chem Soc 1980; 102: 1553-1557.

29) van Kemenade MJJM, de Bruyn PL. A kinetic study of precipitation from supersaturated calcium phosphate solution. J Colloid Interface Sci 1987; 118: 564-585.

30) Wei D, Zhou Y, Jia D, Wang Y. Effect of heat treatment on the structure and in vitro bioactivity of microarc-oxidized (MAO) titania coatings containing $\mathrm{Ca}$ and $\mathrm{P}$ ions. Sur Coat Tech 2007; 201: 8723-8729.

31) Chen XB, Li YC, Du Plessis J, Hodgson PD, Wen C. Influence of calcium ion deposition on apatite-inducing ability of porous titanium for biomedical applications. Acta Biomater 2009; 5: 1808-1820.

32) Sun J, Han Y, Cui K. Microstructure and apatite-forming ability of the MAO-treated porous titanium. Sur Coat Tech 2008; 202: 4248-4256.

33) Tao XJ, Li SJ, Zheng CY, Fu J, Guo Z, Hao YL, Yang R, Guo ZX. Synthesis of a porous oxide layer on a multifunctional biomedical titanium by micro-arc oxidation. Mater Sci Eng C- Mater Bio Appl 2009; 29: 1923-1934. 